\title{
Agent Risk Taking and Efforts in the Context of Multiple Heterogeneous References
}

\author{
Qiong Wang*, Chengyuan Wang*\#, Liang Wan \\ School of Management, University of Science and Technology of China, Hefei, China \\ Email: " wangcyustc@163.com
}

Received 11 October 2014; revised 8 November 2014; accepted 1 December 2014

Copyright (C) 2014 by authors and Scientific Research Publishing Inc.

This work is licensed under the Creative Commons Attribution International License (CC BY). http://creativecommons.org/licenses/by/4.0/

(c) (i) Open Access

\begin{abstract}
The purpose of this paper is to discuss agent risk taking and efforts in the context of multiple heterogeneous references. We focus on two key references in terms of performance target and aspiration income. And we also introduce them into the principal-agent model. By the method of numerical simulation, our results show that performance target and the gap of psychological reference income have complex interaction influences on agent risk taking and efforts. In addition, profit-sharing coefficient plays moderating role in these complex relationships. Our results also provide good evidence and supplement to Pepper and Gore's proposition.
\end{abstract}

\section{Keywords}

Behavioral Agency, Multiple Heterogeneous References, Risk Taking, Agent Efforts

\section{Introduction}

According to Prospect Theory [1] and Behavioral Agency Theory [2], agent would form a gain-loss frame based on a psychological reference point, rather than the final expectation when he/she makes behavioral decisions. This phenomenon can be reflected in the decision process of agent risk taking and efforts [3]. Kahneman and Tversky (1979) have suggested that the reference point could not be only the status quo of decision maker, but an expectation or aspiration level and etc. [1]. Scholars afterwards have extended the derivation of agent's reference point to various contents, including relative pay [2] [4], history performance [3], target difficulty [5]-[8], goal progress [9], incentive forms [10] [11].

However, exiting studies were all concentrated on single reference point. A very few studies have argued that agent would be available to frame problems with multiple reference points [12]-[16], and hence presented a

\footnotetext{
*Qiong Wang and Chengyuan Wang contributed equally to this paper.

"Corresponding author.
}

How to cite this paper: Wang, Q., Wang, C.Y. and Wan, L. (2014) Agent Risk Taking and Efforts in the Context of Multiple Heterogeneous References. Journal of Service Science and Management, 7, 411-418. 
complex pattern of risk behaviors. The reference points in each of these finite studies are with uniform property that we define as syngeneic references, e.g. all about performance (e.g. current performance, industry performance, target performance or performance expectations/aspirations) or about gain/loss of prior enterprise profits.

In this paper, we consider the context of multiple heterogeneous references, in which agent decides risk taking and their efforts based on diversiform yet relative referents with different properties. Such dilemma context is general such as agent obliges to balance the performance target pressured against his aspiration for pay. We introduce two key referents in terms of performance target and aspiration income into principal-agent model. Our results show that performance target, aspiration income and profit-sharing coefficient have complex interaction effects on agents risk taking and their efforts.

\section{Modeling}

We posit that output $\pi=h+\theta$, where $h$ represents agent efforts and $\theta$ is the outcome variable of agent risktaking $u$. The variable $\theta$ has contained stochastic disturbance and is uniformly distributed on the interval $\left[u-3 u^{2}, u+u^{2}\right] \quad(u>0)$. The variable $\theta$ owns a set of good characters, and we define that: agent prefers low (or rational) risk taking when $0<u<1$, for $E(\theta)=u-u^{2}>0$ and $P(E(\theta)>0)>P(E(\theta)<0)$; agent prefers excessive risk taking if $u>1$, for $E(\theta)<0$ and $P(E(\theta)>0)<P(E(\theta)<0)$; and agent makes risk-free choice if $u=1$, for $E(\theta)=0$ and $P(E(\theta)>0)=P(E(\theta)<0)=\frac{1}{2}$. In Pepper and Gore' (2012) study, principal is risk neutral, and they argued that expected income of agent's risk taking would be maximized when $u=1$.

We consider an asymmetric and more pragmatic compensation of agent that given by:

$$
s(\pi)= \begin{cases}\alpha+\beta(\pi-\hat{\pi}) & \pi \geq \hat{\pi} \\ \alpha & \pi<\hat{\pi}\end{cases}
$$

where $\alpha$ is fix salary, $\beta$ is the profit-sharing coefficient, and $\hat{\pi}$ represents performance target.

According to the Behavioral Agency Theory [2], agent is loss averse and reference dependence. Hence, we assume the value function of agent is:

$$
v(x)= \begin{cases}x-T & x \geq T \\ \lambda(x-T) & x<T\end{cases}
$$

where $T$ is the reference point.

We follow Dittmann et al. (2010) to separate effort-disutility from the income utility [17]. Meanwhile, according to the independent action of multi-references [14], we divide the agency utility into three parts: performance achieved utility $g(\hat{\pi})$, pay satisfaction utility $h(s(\pi))$, and effort disutility $c(h)$. Consequently, the total utility of agent is given by:

$$
U\left(h, u ; \alpha, \beta, \hat{\pi}, T_{A}\right)=g(\hat{\pi})+h(s(\hat{\pi}))+c(h)
$$

where

$$
g(\hat{\pi})=\int_{\hat{\pi}}^{h+u+u^{2}}(\pi-\hat{\pi}) f(\pi) \mathrm{d} \pi+\int_{h+u-3 u^{2}}^{\hat{\pi}} \lambda(\pi-\hat{\pi}) f(\pi) \mathrm{d} \pi=\int_{\hat{\pi}}^{h+u+u^{2}}(\pi-\hat{\pi}) \frac{1}{4 u^{2}} \mathrm{~d} \pi+\lambda \int_{h+u-3 u^{2}}^{\hat{\pi}}(\pi-\hat{\pi}) \mathrm{d} \pi
$$

(The expression of $g(\hat{\pi})$ is from $v(x)$ which is the value function of agent, and $f(\pi)=\frac{1}{4 u^{2}}$, which is the probability density function of $\pi$ )

$$
\begin{aligned}
h(s(\pi)) & =\int_{T_{A}}^{\alpha+\beta\left(h+u+u^{2}-\hat{\pi}\right)}\left(s(\pi)-T_{A}\right) f(s(\pi)) \mathrm{d} s(\pi)+\int_{\alpha}^{T_{A}} \lambda\left(s(\pi)-T_{A}\right) f(s(\pi)) \mathrm{d} s(\pi) \\
& =\int_{T_{A}}^{\alpha+\beta\left(h+u+u^{2}-\hat{\pi}\right)}\left(s(\pi)-T_{A}\right) \frac{1}{4 u^{2} \beta} \mathrm{d} s(\pi)+\lambda \int_{\alpha}^{T_{A}}\left(s(\pi)-T_{A}\right) \frac{1}{4 u^{2} \beta} \mathrm{d} s(\pi),
\end{aligned}
$$


( $T_{A}$ is agent's aspiration income, and $f(s(\pi))$ is the probability density function of $s(\pi)$ )

We get

$$
c(h)=-\frac{1}{2} h^{2}
$$

$$
U(h, u ; \beta, \hat{\pi}, t)=-\frac{1}{2} h^{2}+\frac{\left(h+u+u^{2}-\hat{\pi}\right)^{2}-\lambda\left(h+u-3 u^{2}-\hat{\pi}\right)^{2}}{8 u^{2}}+\frac{\left[\beta\left(h+u+u^{2}-\hat{\pi}\right)-t\right]^{2}-\lambda t^{2}}{8 u^{2} \beta}
$$

where $t=T_{A}-\alpha$.

\section{Propositions}

Definition 1: $T_{A}-\alpha$ denotes the gap of psychological reference income of agent, and is taken as a whole ${ }^{1}$.

To maximize $U(h, u ; \beta, \hat{\pi}, t)$, if and only if

$$
\begin{aligned}
\frac{U(h, u ; \beta, \hat{\pi}, t)}{\partial h}= & \frac{(1+\beta)\left(h+u+u^{2}-\hat{\pi}\right)-\lambda\left(h+u-3 u^{2}-\hat{\pi}\right)-t}{4 u^{2}}-h=0 \\
\frac{U(h, u ; \beta, \hat{\pi}, t)}{\partial u}= & \frac{(2 u+1)(1+\beta)\left(h+u+u^{2}-\hat{\pi}\right)+\lambda(6 u-1)\left(h+u-3 u^{2}-\hat{\pi}\right)-(2 u+1) t}{4 u^{2}} \\
& -\frac{\left(h+u+u^{2}-\hat{\pi}\right)^{2}-\lambda\left(h+u-3 u^{2}-\hat{\pi}\right)^{2}}{4 u^{3}}+\frac{\lambda t^{2}-\left(t-\beta\left(h+u+u^{2}-\hat{\pi}\right)\right)^{2}}{4 \beta u^{3}}=0 .
\end{aligned}
$$

where $t=T_{A}-\alpha$.

Equations (1) and (2) have no explicit solution. Thus, we conduct analyses on relationships among these variables by the method of numerical simulation. We utilize the method of interior point algorithm ${ }^{2}$ through Matlab 2012b, and the parameter assignments are as follows:

$$
\begin{gathered}
\lambda=2.25 \quad(\lambda>1) \\
\beta=0.1,0.2,0.3,0.4,0.5 \quad(0<\beta<1) \\
t=0,0.1,0.2,0.3,0.4,0.5,0.6,0.7,0.8,0.9,1 \quad(t=T-\alpha, 0<T<1,0<\alpha<1) \\
\hat{\pi}=0,1,2,3,4,5,6,7,8,9,10 \quad(\hat{\pi} \geq 0)^{3}
\end{gathered}
$$

Additionally, variables must satisfy

$$
-3 u^{2}+u+h \leq \hat{\pi} \leq h+u+u^{2} \text {, and } 0 \leq t \leq \beta\left(h+u+u^{2}-\hat{\pi}\right) .
$$

\section{Proposition 1:}

a. $T_{A}-\alpha$ has positive relationship with $u$, and influences positively on $h$ under high level of $\hat{\pi}$ and has U-shaped influence on $h$ under low level of $\hat{\pi}$.

b. Both $\hat{\pi}$ and $\beta$ have moderating effects on the influence of $T_{A}-\alpha$ on $u$ and $h$.

Under high level of $\hat{\pi}, u$ and $h$ are positively influenced by $T_{A}-\alpha$, and the increase of $\beta$ significantly weakens this influence(see Figure 1(a) and Figure 1(b)). Under low level of $\hat{\pi}, T_{A}-\alpha$ has positive effect on $u$, while is complex correlated with $h$ (see Figure 1(c) and Figure 1(d)). In addition, the increase of $\beta$ intensifies the effect of low-level $T_{A}-\alpha$ while outstandingly weakens the effect of high-level $T_{A}-\alpha$ on $u$ and $h$, and even leads to the U-shaped relation between $T_{A}-\alpha$ and $h$.

\footnotetext{
${ }^{1}$ In fact, previous studies have implemented similar process but without clear definition [18].

${ }^{2}$ This method is used to solve linear and nonlinear convex optimization problems.

${ }^{3}$ First, $\quad \lambda=2.5$ derives from the experiment results of Kahneman and Tversky (1979). Second, we do not build withdrawal mechanism, and hence the values of $\hat{\pi}$ or $t$ are deemed as in an acceptable range. Third, we test much more sets of assignments and conclude that above assignments are appropriate and able to present the relations of variables.
} 


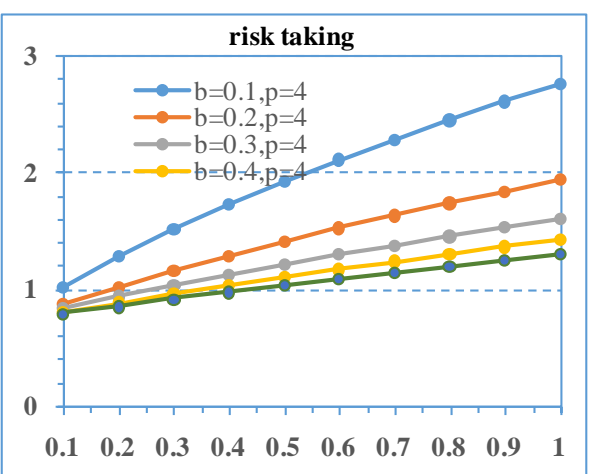

(a)

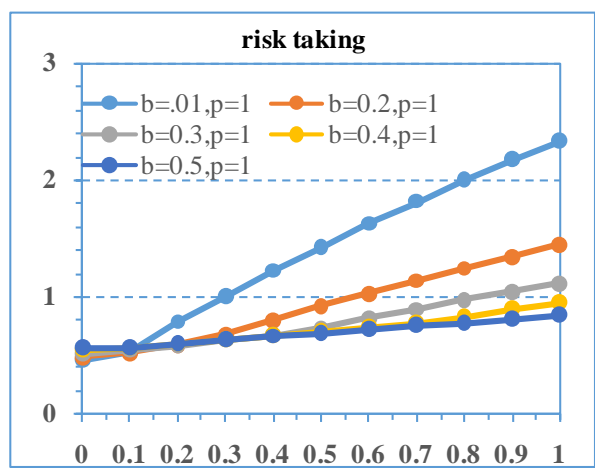

(c)

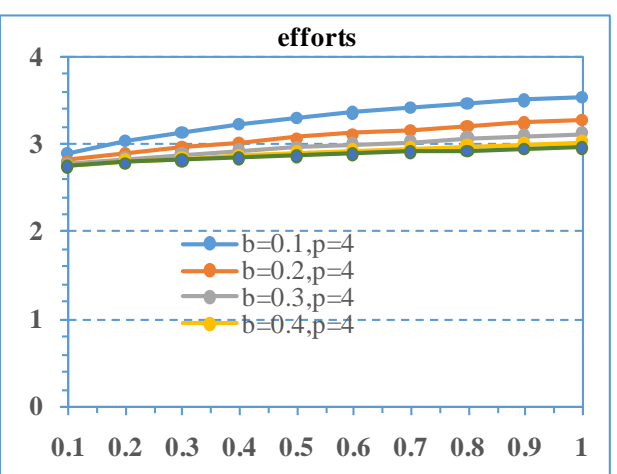

(b)

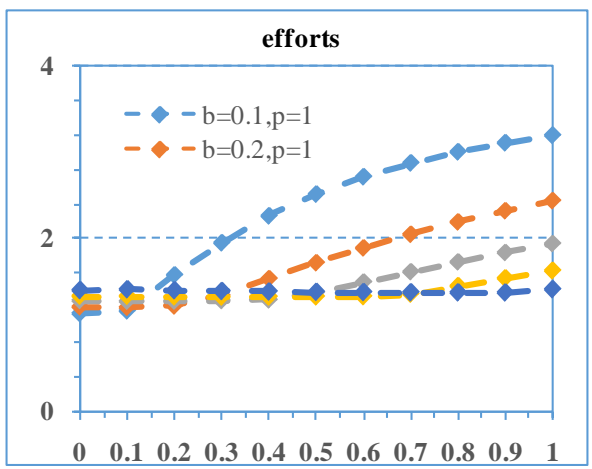

(d)

Figure 1. (a) $x, y$-axis are respectively $T_{A}-\alpha$ and $u$; (b) $x, y$-axis are respectively $T_{A}-\alpha$ and $h$. (Note: $b$ represents $\beta$ and $p$ represents $\hat{\pi}$, similarly hereinafter); (c) $x, y$-axis are respectively $T_{A}-\alpha$ and $u$; (d) $x, y$-axis are respectively $T_{A}-\alpha$ and $h$.

\section{Proposition 2:}

a. $\hat{\pi}$ is positively related with $u$ under a lower level of $\beta$, while has U-shaped relationship with $u$ if $\beta$ exceeds a certain point. Meanwhile, the influence of $\hat{\pi}$ on $u$ is weakened by the increase of $\beta$ (see Figure 2(a)).

b. Under a certain level of $\beta$, agent takes rational risk when $\hat{\pi}$ is low and prefers excessive risk taking when $\hat{\pi}$ increases to a high level (see Figure 2(b)).

c. $h$ enhances with the increase of $\hat{\pi}$. Moreover, $\beta$ negatively moderates the influence at the high-level $\hat{\pi}$, and has U-shaped moderating effects at the low-level $\hat{\pi}$ (see Figure 2(c)).

d. The influence of $\hat{\pi}$ on $u$ and $h$ is moderated by $T_{A}-\alpha$, and the moderating effect would decrease and approach to 0 after a culmination (see Figure 2(d)).

Proposition 3: When agent faces "dilemma reference dependence", i.e.

a. The gap of psychological reference income of agent is satisfied (i.e. $T_{A}-\alpha=0$ ) while agent faces a pressurized performance target $(\hat{\pi} \geq 4)$ : agent enhances $u$ and $h$ with the increase of $\hat{\pi}$, and even takes excessive risk. Simultaneously, $\beta$ has no longer moderating effects (see Figure 3(a) and Figure 3(b)).

b. Agent has stress-free performance target (i.e. $\hat{\pi}=0$ ) while the gap of psychological reference income is not met $\left(T_{A}-\alpha>0\right): u$ and $h$ raises with the increase of $T_{A}-\alpha$. The relationship is signally weakened by $\beta$ at high-level $T_{A}-\alpha$, and strengthened in a minor degree when $T_{A}-\alpha$ is low (see Figure 3(c) and Figure $3(\mathrm{~d})$ ).

\section{Proposition 4:}

Appropriate weak incentive accompanied with a moderate performance target is a more effective way to motivate agent to pay more efforts and adopt opportune level of risk taking.

Previous studies have also concluded comparable propositions from multi-aspects ${ }^{4}$. We demonstrate the ${ }^{4}$ These factors include exogenous ones, such as multitasking [19], the complexity and difficulty to measure performance [20], and benefit for enterprise centralizing [21]; and endogenous ones, such as knowledge constraints [2]. 


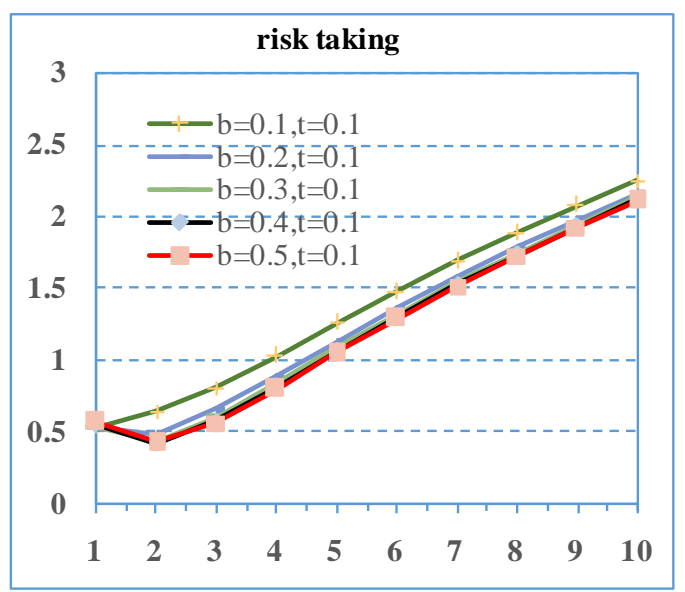

(a)

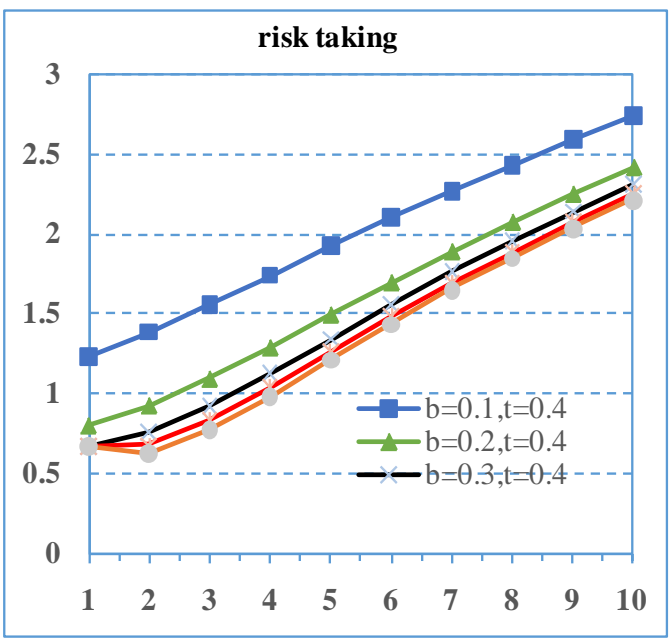

(c)

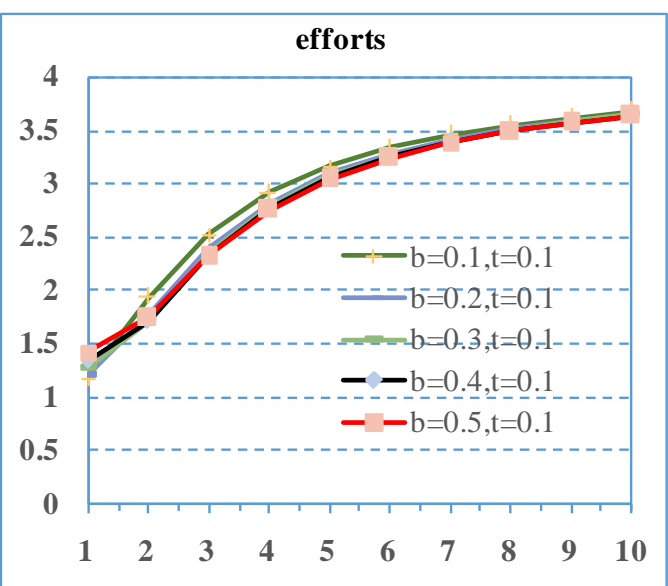

(b)

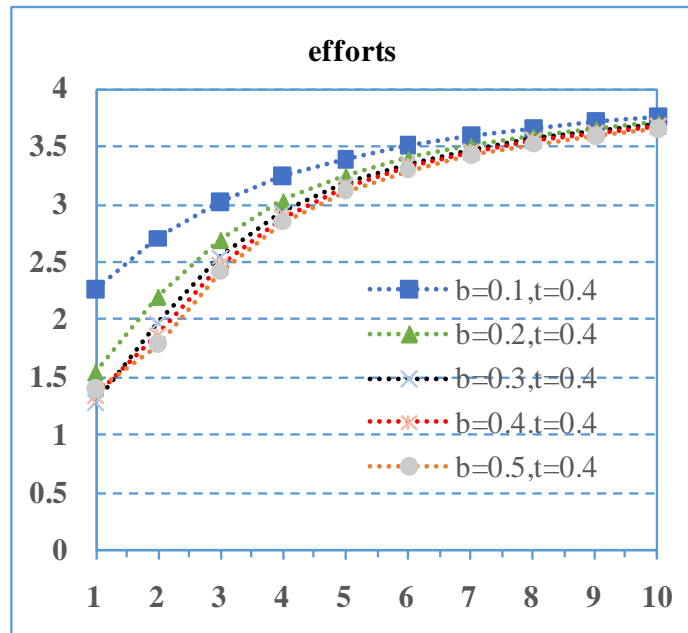

(d)

Figure 2. (a) $x, y$-axis are respectively $\hat{\pi}$ and $u$; (b) $x, y$-axis are respectively $\hat{\pi}$ and $h$. (Note: $t$ represents $T_{A}-\alpha$, and similarly hereinafter); (c) $x, y$-axis are respectively $\hat{\pi}$ and $u$; (d) $x, y$-axis are respectively $\hat{\pi}$ and $h$.

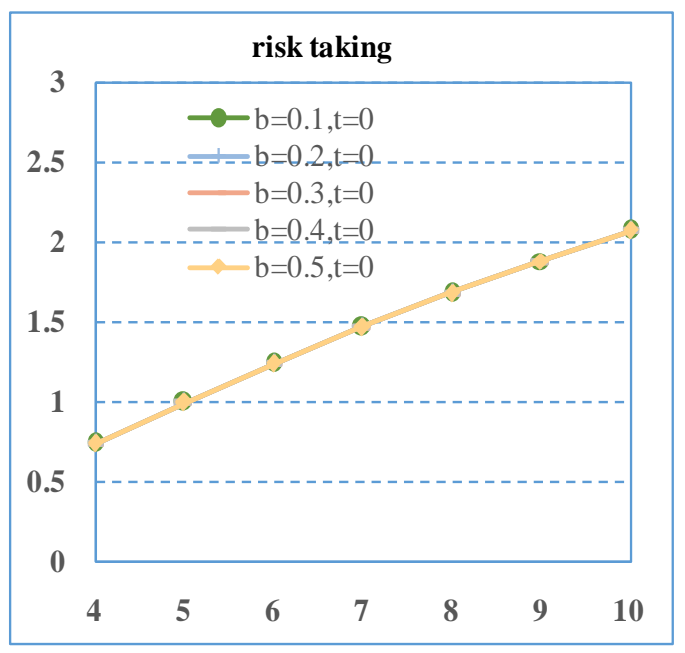

(a)

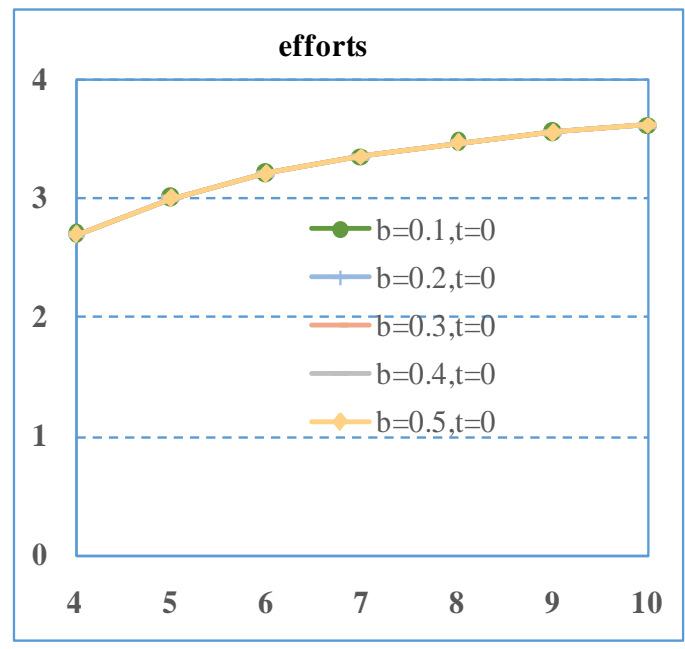

(b) 


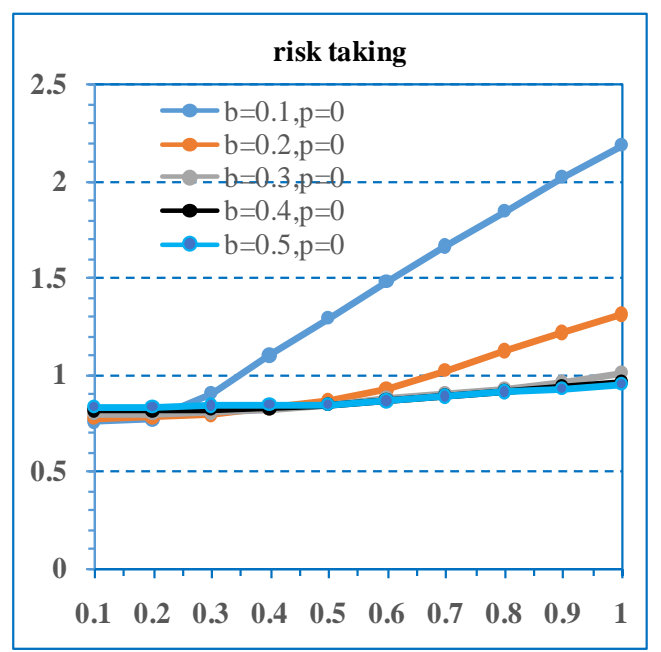

(c)

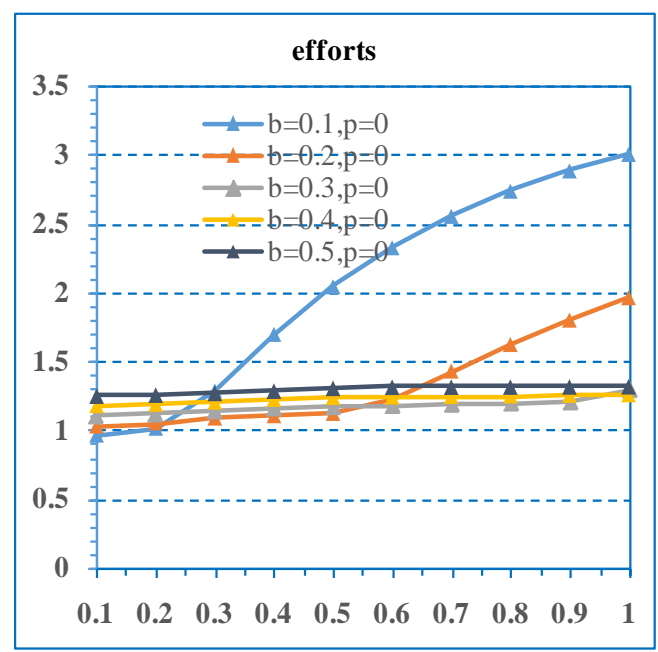

(d)

Figure 3. (a) $x, y$-axis are respectively $\hat{\pi}$ and $u$; (b) $x, y$-axis are respectively $\hat{\pi}$ and $h$; (c) $x, y$-axis are respectively $T_{A}-\alpha$ and $u$; (d) $x, y$-axis are respectively $T_{A}-\alpha$ and $h$.

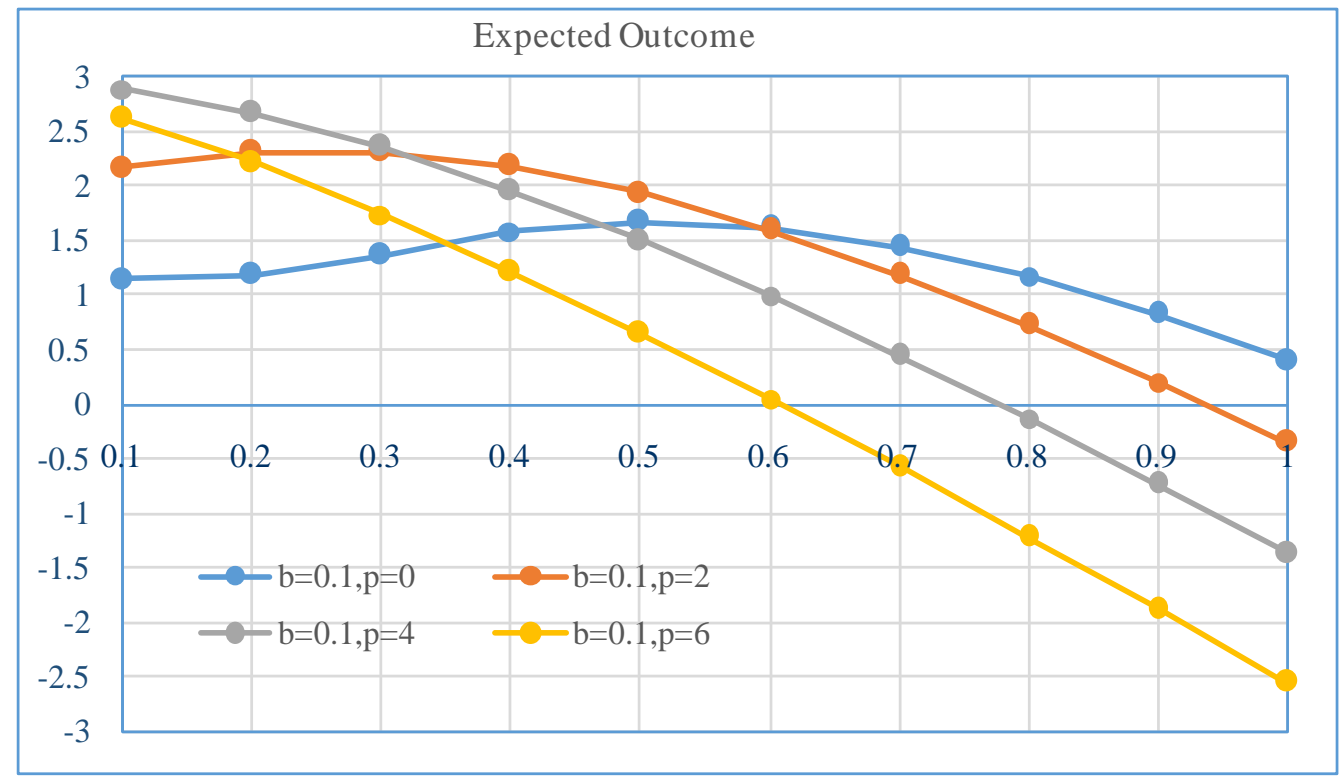

Figure 4. $x, y$-axis are respectively $T_{A}-\alpha$ and expected outcome.

proposition of Pepper and Gore (2012) who put forward that there is a set of first-best compensation strategies [2]. $T_{A}-\alpha$ and $\hat{\pi}$ must be set at the most appropriate level to maximize expected outcomes. Otherwise, negative outcomes generated by excessive risk taking may surpass the performance growth brought by efforts, and the optimal level of risk taking and efforts cannot be stimulated if $T_{A}-\alpha$ and $\hat{\pi}$ is below the certain level (Figure 4).

\section{Conclusion}

To sum up, the mechanisms of agent risk taking and efforts are more complex in the context of multiple heterogeneous references. As shown in Figure 5, a conceptual model is provided to integrate these complex relationships. Specifically, performance target and the gap of psychological reference income have interaction effects on agent risk taking and efforts. In addition, profit-sharing coefficient plays moderating roles in these interaction 


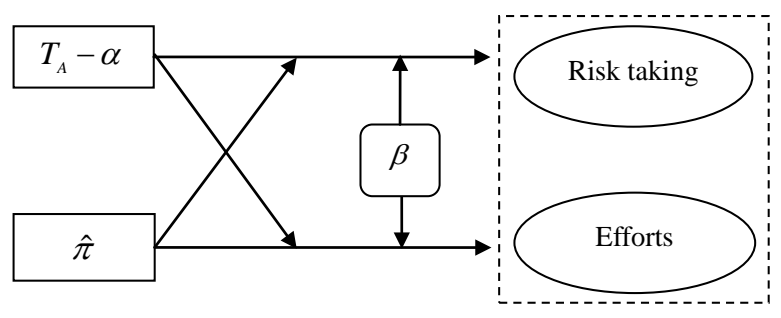

Figure 5. The integrated model.

relationships. Our results also provide good evidence and supplement to the proposition of Pepper and Gore (2012).

\section{References}

[1] Kahneman, D. and Tversky, A. (1979) Prospect Theory: An Analysis of Decision under Risk. Econometrica, 47, 263292. http://dx.doi.org/10.2307/1914185

[2] Pepper, A. and Gore, J. (2012) Behavioral Agency Theory: New Foundations for Theorizing about Executive Compensation. Journal of Management.

[3] Wiseman, R.M. and Gomez-Mejia, L.R. (1998) A Behavioral Agency Model of Managerial Risk Taking. Academy of Management Review, 23, 133-153.

[4] Fong, E.A. (2010) Relative CEO Underpayment and CEO Behaviour towards R\&D Spending. Journal of Management Studies, 47, 1095-1122. http://dx.doi.org/10.1111/j.1467-6486.2009.00861.X

[5] Knight, D., Durham, C.C. and Locke1, E.A. (2001) The Relationship of Team Goals, Incentives, and Efficacy to Strategic Risk, Tactical Implementation, and Performance. Academy of Management Journal, 44, 326-338. http://dx.doi.org/10.2307/3069459

[6] Larrick, R.P., Heath, C. and Wu, G. (2009) Goal-Induced Risk Taking in Negotiation and Decision Making. Social Cognition, 27, 342-364. http://dx.doi.org/10.1521/soco.2009.27.3.342

[7] Rablen, M.D. (2010) Performance Targets, Effort and Risk-Taking. Journal of Economic Psychology, 31, $687-697$. http://dx.doi.org/10.1016/j.joep.2010.05.002

[8] Larraza-Kintana, M., Gomez-Mejia, L.R. and Wiseman, R.M. (2011) Compensation Framing and the Risk-Taking Behavior of the CEO: Testing the Influence of Alternative Reference Points. The Journal of the Iberoamerican Academy of Management, 9, 32-55.

[9] Shapira, Z. (2002) Aspiration Levels and Risk Taking by Government Bond Traders. Hebrew University of Jerusalem, Center for Rationality and Interactive Decision Theory.

[10] Chen, C.R., Steiner, T.L. and Whyte, A.M. (2006) Does Stock Option-Based Executive Compensation Induce RiskTaking? An Analysis of the Banking Industry. Journal of Banking \& Finance, 30, 915-945. http://dx.doi.org/10.1016/j.jbankfin.2005.06.004

[11] Lefebvre, M. and Vieider, F.M. (2011) Risk Taking of Executives under Different Incentive Contracts: Experimental Evidence. Journal of Economic Behavior \& Organization, 97, 27-36.

[12] Bromiley, P. (1991) Testing a Causal Model of Corporate Risk Taking and Performance. Academy of Management Journal, 34, 37-59. http://dx.doi.org/10.2307/256301

[13] Heath, C., Larrick, R.P. and Wu, G. (1999) Goals as Reference Points. Cognitive Psychology, 38, 79-109. http://dx.doi.org/10.1006/cogp.1998.0708

[14] Ordonez, L., Connolly, T. and Coughlan, R. (2000) Multiple Reference Points in Satisfaction and Fairness Assessment. Journal of Behavioral Decision Making, 13, 329-344. http://dx.doi.org/10.1002/1099-0771(200007/09)13:3<329::AID-BDM356>3.0.CO;2-Q

[15] Sullivan, K. and Kida, T. (1995) The Effect of Multiple Reference Points and Prior Gains and Losses on Managers' Risky Decision Making. Organizational Behavior and Human Decision Processes, 64, 76-83. http://dx.doi.org/10.1006/obhd.1995.1091

[16] Lin, C.-H., Huang, W.-H. and Zeelenberg, M. (2006) Multiple Reference Points in Investor Regret. Journal of Economic Psychology, 27, 781-792. http://dx.doi.org/10.1016/j.joep.2006.03.004

[17] Dittmann, I., Maug, E. and Spal, O. (2010) Sticks or Carrots? Optimal CEO Compensation When Managers Are Loss Averse. The Journal of Finance, 65, 2015-2050. http://dx.doi.org/10.1111/j.1540-6261.2010.01609.x 
[18] Larraza-Kintana, M., Wiseman, R.M., Gomez-Mejia, L.R. and Welbourne, T.M. (2007) Disentangling Compensation and Employment Risks Using the Behavioral Agency Model. Strategic Management Journal, 28, 1001-1019. http://dx.doi.org/10.1002/smj.624

[19] Holmstrom, B. and Milgrom, P. (1994) The Firm as an Incentive System. The American Economic Review, 84, 972991.

[20] Roberts, J. (2010) Designing Incentives in Organizations. Journal of Institutional Economics, 6, 125. http://dx.doi.org/10.1017/S1744137409990221

[21] Steen, E.V.D. (2007) Interpersonal Authority in a Theory of the Firm. American Economic Review, 100, $466-490$. 
Scientific Research Publishing (SCIRP) is one of the largest Open Access journal publishers. It is currently publishing more than 200 open access, online, peer-reviewed journals covering a wide range of academic disciplines. SCIRP serves the worldwide academic communities and contributes to the progress and application of science with its publication.

Other selected journals from SCIRP are listed as below. Submit your manuscript to us via either submit@scirp.org or Online Submission Portal.
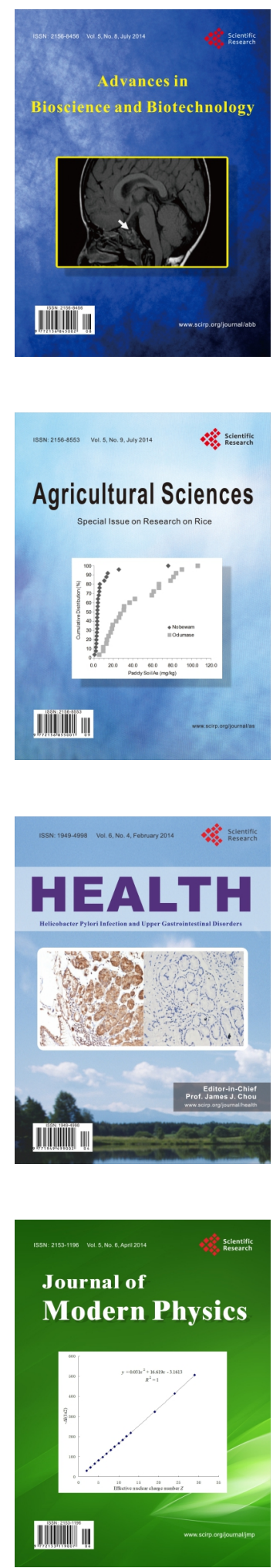
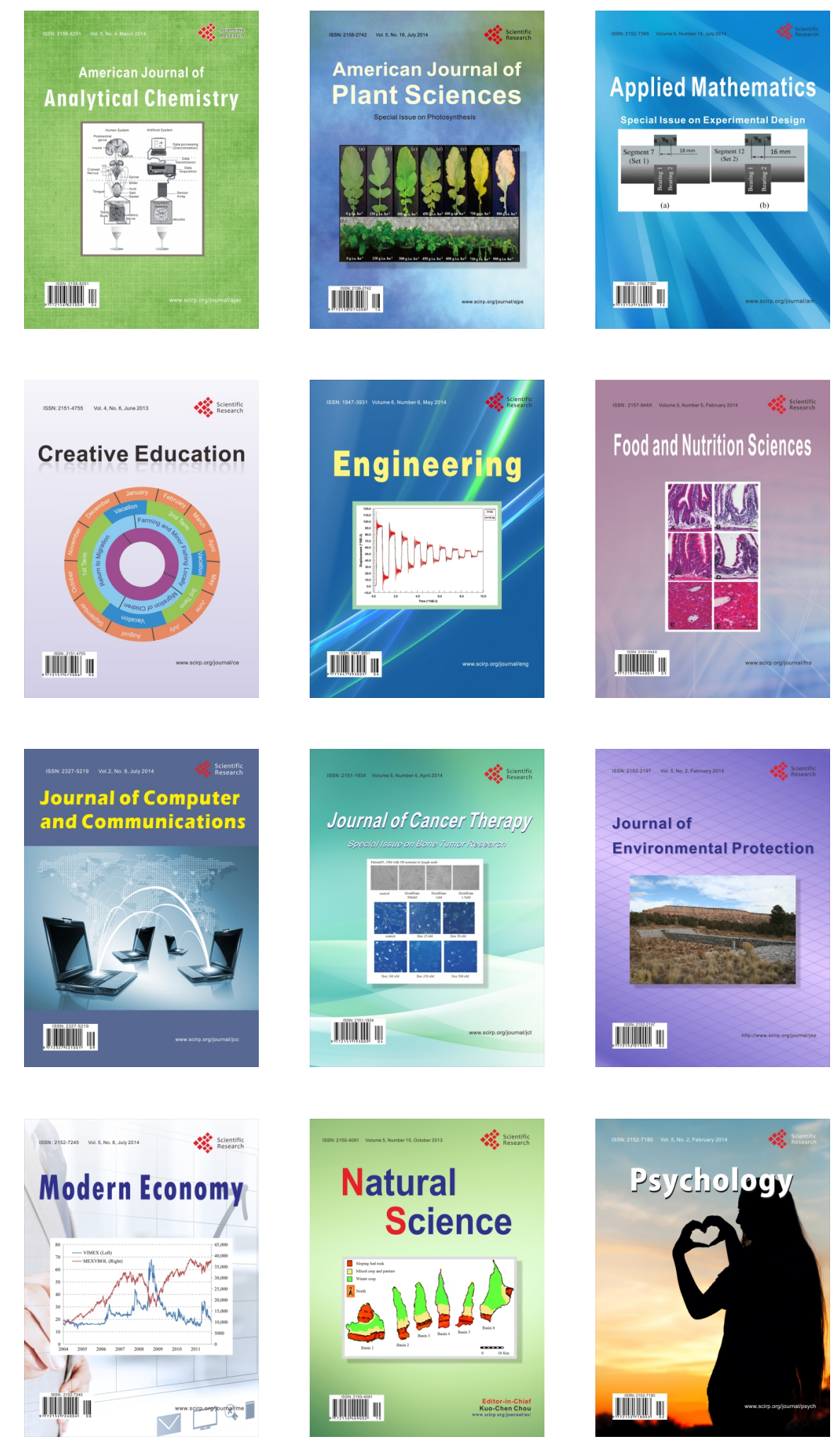